\title{
Os 20 Anos do SUS e a Odontologia do Trabalho
}

\section{The 20 Years of SUS and a Dental Work}

\author{
Sylvio da Costa Júnior ${ }^{1}$ \\ Marcos Nascimento e Silva ${ }^{2}$ \\ Eduardo Meohas ${ }^{3}$
}

Palavras-chave:

Resumo

SUS

Integralidade

Odontologia do Trabalho
O presente trabalho se propõe a fazer um paralelo entre a construção histórica do Sistema Único de Saúde brasileiro e o processo de mecanização e modernização do trabalho, especialmente no Brasil, para que possamos, a partir dessas reconstruções históricas, entendermos como a Odontologia do Trabalho se insere como importante ferramenta e instrumento para a qualidade de vida deste "novo" trabalhador, exposto a novas patologias e a novas formas e relações de trabalho moderno. Não temos a pretensão, neste estudo, de detalharmos, passo a passo, a modernização do Brasil com interface nas respectivas conjunturas políticas, mas sim, de atentarmos para como o Brasil instalou e transformou seu parque industrial e, como neste cenário, a saúde do trabalhador necessita também avançar, e ser entendida de maneira mais ampla, do que somente a ausência de patologias. Nesse espectro, a Odontologia do Trabalho se coloca como forte ferramenta para concretização do direito constitucional ligado, principalmente, a integralidade da assistência.

\section{Abstract}

This paper aims to draw a parallel between the historical construction of the Unified Health System and the process of modernization and mechanization of labor, especially in Brazil, so that we can from these historical reconstructions, we understand how the dental work is part as an important tool and an instrument for quality of life of this "new" worker, exposed to new diseases and new forms and relations of modern work. We do not claim this study, a detailed, step by step, the modernization of Brazil in their interface with political circumstances, but to attend to such as Brazil and has installed its industrial park and, as in this scenario, the worker's health also need to advance, and be understood more broadly than just the absence of pathology. In the spectrum of dental work stands as a strong tool for implementing the constitutional right on, especially the comprehensive care.
Key words:

SUS

completeness

Occupational

Dentistry
Artigo
Original

Original

Paper

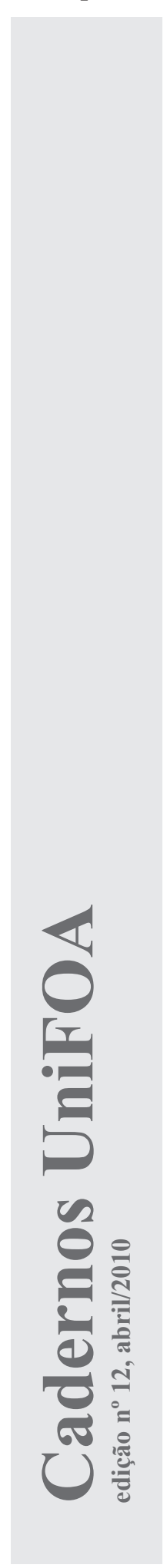

\footnotetext{
${ }^{1}$ Odontólogo, Especialista em Saúde da Família pelo UniFOA/RJ e Mestrando em Saúde da Família da Universidade Estácio de Sá/RJ.

${ }^{2}$ Médico, Especialista em Saúde da Família pelo UniFOA/RJ

${ }^{3}$ Médico, Hematologista e Mestrando em Saúde da Família da Universidade Estácio de Sá/RJ.
}

palavra, saúde. Além da simplista avaliação de que saúde é tratar doentes e doenças, podemos dizer também que saúde é dar às pessoas, trabalhadores ou não, qualidade de vida. Algumas perguntas surgem quando pensamos no atendimento à saúde, como: quem são essas pessoas que atendem aos doentes? Qual a com distintos resultados, pois, muitos fatores estão diretamente ligados a essa simples 
formação desse profissional? Quais patologias atingem mais a população? $\mathrm{O}$ trabalho das pessoas tem relação com a qualidade de vida? $\mathrm{O}$ mesmo trabalho tem reação com a doença dessa pessoa? Como isso pode ser prontamente diagnosticado e tratado? Há como avaliar se uma prática cotidiana é insalubre?

Por trás da questão- saúde - há indústrias inteiras, de medicamentos, planos de saúde e hospitais; por exemplo, que movimentam montanhas de dinheiros. Tratar do tema saúde é antes de tudo tratar de interesses, que podem ser legítimos ou não.

A construção dos sistemas de saúde nos países, de um modo geral, ocorre de modo muito diferente, variando no mundo todo. Alguns países, como Brasil e Espanha, criaram sistemas que dão atendimento integral e universalista a sua população; outros, como a Alemanha, mantém há mais de um século um sistema de saúde muito parecido com os IAPs, (Instituto de Aposentadorias e Pensões) da era Vargas, onde os trabalhadores se organizam e são atendidos de acordo com seu ramo de trabalho e respectiva contribuição (Giovanella, 1998); outros ainda, como os Estados Unidos, não têm sistema público algum e as pessoas têm que pagar seus planos de saúde para poderem ter algum tipo de atendimento médico-hospitalar (Rodrigues, 2009). Tanto em países como Alemanha e Estados Unidos, quem está fora da cobertura privada de saúde fica exposto a uma série de dificuldades, sendo muita das vezes acolhida por políticas de assistência social (Giovanella, 1998).

Para este estudo, é fundamental entender como ocorreu a transformação de um país com uma população - há menos de 100 anos predominantemente rural, com sua economia alicerçada na agriculturaque migra para as cidades e passa a ter um majoritário componente urbano e citadino, pois, essa mudança de rumo/trabalho/ economia traz implicações nas novas formas de promover saúde e qualidade de vida. Frente aos desafios desse novo Brasil industrial e citadino, a Odontologia do Trabalho tem papel relevante para a promoção e atenção à saúde.

\section{Proposição}

O objetivo deste trabalho foi estudar a evolução das políticas públicas em saúde no Brasil e a construção de um sistema público universalista, em que, frente aos novos desafios do trabalho e do papel estatal, o conceito da integralidade da atenção e da continuidade do cuidado tenha na Odontologia do Trabalho um importante instrumento e ferramenta para que esse preceito constitucional possa ser atendido.

\section{Revisão de Literatura}

O SUS é um sistema público, organizado e orientado no sentido do interesse coletivo, $\mathrm{e}$, todas as pessoas, independente de raça, crenças, cor, situação de emprego, classe social, local de moradia, a ele têm direito (Lei nº080, de 19 de setembro de 1990). Antes do advento do Sistema Único de Saúde (SUS), a atuação do Ministério da Saúde se resumia às atividades de promoção de saúde e prevenção de doenças (por exemplo, campanhas de vacinação), realizadas em caráter universal; e à assistência médico-hospitalar para poucas doenças; servia aos indigentes, ou seja, a quem não tinha acesso ao atendimento pelo Instituto Nacional de Assistência Médica da Previdência Social (Levcovitz et al., 2001). O INAMPS foi criado pelo regime militar em 1974 pelo desmembramento do Instituto Nacional de Previdência Social (INPS), que hoje é o Instituto Nacional de Seguridade Social (INSS); era uma autarquia filiada ao Ministério da Previdência e Assistência Social (hoje Ministério da Previdência Social) e tinha a finalidade de prestar atendimento médico aos que contribuíam com a previdência social, ou seja, aos empregados de carteira assinada. O INAMPS dispunha de estabelecimentos próprios, mas, a maior parte do atendimento era realizado pela iniciativa privada; os convênios estabeleciam a remuneração por procedimento (Levcovitz, 1997).

O movimento da Reforma Sanitária nasceu no meio acadêmico, no início da década de 70, como forma de oposição técnica e política ao regime militar, sendo 
abraçado por outros setores da sociedade e pelo partido de oposição da época - o Movimento Democrático Brasileiro (MDB). Somente com a intensificação da transição democrática foram criadas condições sociais e políticas que permitiram o desenvolvimento da proposta da Reforma Sanitária. O movimento sanitário resultou da mobilização e da uniformização gradual de diversos movimentos de setores distintos da sociedade. Ele resultou da mobilização do movimento de moradores das grandes cidades, estudantes, médicos, professores universitários e fúncionários do INAMPS.

\section{Movimentos populares pela saúde: (Rodrigues, 2009)}

1978: I Encontro Sobre as Condições de saúde em São Paulo

1979: I Encontro de Experiências de Medicina Comunitária (ENEMEC)

1980: manifestação dos moradores da Baixada Fluninense no Palácio da Guanabara por melhores condições de saúde e saneamento; I Encontro Popular de Saúdedo Estado do Rio de Janeiro

1980-1986: 3 ENEMECs e mais 3 Encontros Nacionais do Movimento Popular em Saúde (MOPS)

1984: Comitê Político de Saneamento da Baixada Fluminense; nova passeata vai da Central do Brasil até o Palácio da Guanabara exigindo melhores condições de saúde e saneamento para a área

1986-1987:Fórum Popular pela Saúde (Guerschman, 1995)

Em meados da década de 70, ocorreu uma crise do financiamento da previdência social, com repercussões no INAMPS. Em 1979, o general João Baptista Figueiredo assumiu a presidência com a promessa de abertura política e, de fato, a Comissão de Saúde da Câmara dos Deputados promoveu, no período de 9 a 11 de outubro de 1979, o I Simpósio sobre Política Nacional de Saúde, que contou com participação de muitos dos integrantes do movimento e chegou a conclusões altamente favoráveis ao mesmo; ao longo da década de 80,o INAMPS passaria por sucessivas mudanças com universalização progressiva do atendimento, já numa transição com o SUS (Levcovitz, 1997; Guerschman, 1995).

A $8^{\text {a }}$ Conferência Nacional de Saúde foi um marco na história do SUS por vários motivos: foi aberta em 17 de março de 1986 por José Sarney, o primeiro presidente civil após a ditadura, e foi a primeira CNS a ser aberta à sociedade; além disso, foi importante na propagação do movimento da Reforma Sanitária. A $8^{\mathrm{a}} \mathrm{CNS}$ resultou na implantação do Sistema Unificado e Descentralizado de Saúde (SUDS), um convênio entre o INAMPS e os governos estaduais, mas, o mais importante foi ter formado as bases para a seção "Da Saúde" da Constituição brasileira de 5 de outubro de 1988. A Constituição de 1988 foi um marco na história da saúde pública brasileira, ao definir a saúde como "direito de todos e dever do Estado" (Levcovitz, 1997; Santos, 203). A implantação do SUS foi realizada de forma gradual: primeiro veio o SUDS; depois, a incorporação do INAMPS ao Ministério da Saúde (Decreto no 99.060, de 7 de março de 1990); e por fim a Lei Orgânica da Saúde (Lei n ${ }^{\circ}$ 8.080, de 19 de setembro de 1990) fundou o SUS. Em poucos meses, foi lançada a Lei ${ }^{\circ} 8.142$, de 28 de dezembro de 1990, que imprimiu ao SUS uma de suas principais características: o controle social, ou seja, a participação dos usuários (população) na gestão do serviço. O INAMPS só foi extinto em 27 de julho de 1993 pela Lei no 8.689 .

A industrialização brasileira certamente é a história de uma industrialização sui generis, pois nos modernizamos sem reformarmos em três pilares fundamentais do Brasil escravocrata: a reforma fundiária, a reforma tributária e a reforma social (Pochmann, 2008). O Brasil, desde seu descobrimento, se destacou como país exportador de matérias-primas, sempre agrícolas, em um modelo conhecido por plantation, em que são plantados grandes quantidades de monocultura, cana-de-açúcar no Nordeste e café no Sudeste, com viés puramente exportador. A mão de obra nos primeiros 400 anos do Brasil foi à mão de obra escrava. O Brasil vai somente a pouco mais de 100 anos experimentando o trabalho assalariado, onde empregado e empregador têm direitos e deveres mútuos. O trabalho escravo foi a mola propulsora da economia brasileira durante 4/5 de nossa história (Freyre, 2004). A

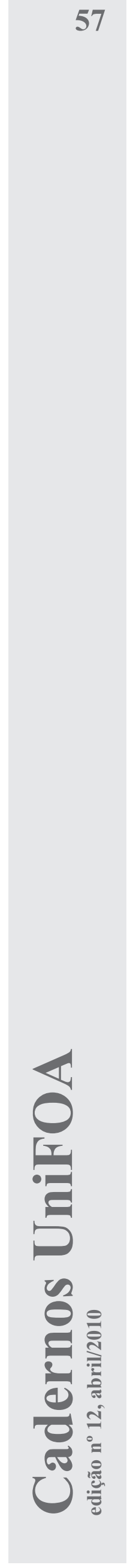


industrialização começa, de forma incipiente, com São Paulo, destinos de milhares de famílias de italianos, principalmente, sendo o embrião do Brasil moderno.

Concomitante ao fim da escravidão em 1888, à mão de obra assalariada e o desembarque dos imigrantes europeus, muitos cafeicultores passaram a investir parte dos lucros, obtidos com a exportação do café, no estabelecimento de indústrias. Eram fábricas de tecidos, calçados e outros produtos de fabricação mais simples (Freyre, 2004).

Foi durante o Governo de Getúlio Vargas, de 1930 a 1945, conhecido como Estado Novo, que a industrialização no Brasil deu um salto (Rodrigues, 2009). Vargas tomou a decisão política de começar a industrialização no Brasil com dois objetivos claros: privilegiar o empresariado nacional e tornar o Brasil menos dependente dos produtos manufaturados estrangeiros, criando aqui, além de um forte mercado consumidor, um mercado também produtor. Porém, esse desenvolvimento continuou restrito aos grandes centros urbanos da região sudeste, provocando uma grande disparidade regional. Durante o governo de Juscelino Kubitschek, JK, (1956-1960) o desenvolvimento industrial brasileiro ganhou novos rumos e feições. JK abriu a economia para o capital internacional, atraindo indústrias multinacionais. Foi durante esse período que ocorreu a instalação de montadoras de veículos internacionais (Ford, General Motors, Volkswagen e Willys) em território brasileiro.

A relação entre o trabalho e a saúde/ doença - constatada desde a Antiguidade e exacerbada a partir da Revolução Industrial - nem sempre se constituiu em foco de atenção. Afinal, no trabalho escravo ou no regime servil, inexistia a preocupação em preservar a saúde dos que eram submetidos ao trabalho, interpretado como castigo ou estigma: o "tripalium", instrumento de tortura. O trabalhador, o escravo ou o servo eram peças de engrenagens "naturais", pertences da terra, assemelhados a animais e ferramentas, sem história, sem progresso, sem perspectivas, sem esperança terrestre, até que, consumidos seus corpos, pudessem voar livres pelos ares ou pelos céus da metafísica (Nosela, 1989).
Com o advento da Revolução Industrial, o trabalhador "livre" para vender sua força de trabalho tornou-se presa da máquina, de seus ritmos, dos ditames da produção que atendiam à necessidade de acumulação rápida de capital e de máximo aproveitamento dos equipamentos, antes de se tornarem obsoletos.

As jornadas extenuantes, em ambientes extremamente desfavoráveis à saúde, às quais se submetiam também mulheres e crianças, eram frequentemente incompatíveis com a vida. A aglomeração humana em espaços inadequados propiciava a acelerada proliferação de doenças infectocontagiosas, ao mesmo tempo em que a periculosidade das máquinas era responsável por mutilações e mortes.

A presença de um médico no interior das unidades fabris representava, ao mesmo tempo, um esforço em detectar os processos danosos à saúde e uma espécie de braço do empresário para recuperação do trabalhador, visando ao seu retorno à linha de produção, num momento em que a força de trabalho era fundamental à industrialização emergente.

Através dos tempos, a atuação do Estado no espaço do trabalho sustentou-se nas concepções dominantes sobre a causalidade das doenças. Essas concepções decorrem tanto da bagagem cumulativa de conhecimentos como do seu caráter de práticas sociais, cujos marcos conceituais definem-se, no bojo de relações peculiares, nos diferentes contextos históricos, onde surgem ou se mantêm.

Assim, a Medicina do Trabalho, centrada na figura do médico, orienta-se pela teoria da unicausalidade, ou seja, para cada doença, um agente etiológico. Transplantada para o âmbito do trabalho, vai refletir-se na propensão a isolar riscos específicos e, dessa forma, atuar sobre suas consequências, medicalizando em função de sintomas e sinais ou, quando muito, associando-os a uma doença legalmente reconhecida.

A rotatividade da mão de obra, sobretudo quando se intensifica a terceirização, representa um obstáculo a mais nesse sentido. A passagem por processos produtivos diversos pode mascarar nexos causais e diluir a possibilidade de estabelecê-los, excetuando-se os mais evidentes e, considerada a hipótese remota de exames admissionais, que levem em conta a 
história laboral pregressa, numa perspectiva ainda mais remota de alimentar um processo de vigilância em saúde do trabalhador. A constatação de doenças na seleção da força de trabalho funciona, na prática, como um recurso para impedir o recrutamento de indivíduos cuja saúde já esteja comprometida.

A Saúde Ocupacional avança numa proposta interdisciplinar, com base na Higiene Industrial, relacionando ambiente de trabalho; corpo do trabalhador. Incorpora a teoria da multicausalidade, na qual um conjunto de fatores de risco é considerado na produção da doença, avaliada através da clínica médica e de indicadores ambientais e biológicos de exposição e efeito. Os fundamentos teóricos de Leavell \& Clark (1976), a partir do modelo da História Natural da Doença, entendem-na, em indivíduos ou grupos, como derivada da interação constante entre o agente, o hospedeiro e o ambiente, significando um aprimoramento da multicausalidade simples.

Mesmo assim, se os agentes/riscos são assumidos como peculiaridades "naturalizadas" de objetos e meios de trabalho, descontextualizados das razões que se situam em sua origem, repetem-se, na prática, as limitações da Medicina do Trabalho. As medidas que deveriam assegurar a saúde do trabalhador, em seu sentido mais amplo, acabamporrestringir-seaintervenções pontuais sobre os riscos mais evidentes. Enfatiza-se a utilização de equipamentos de proteção individual, em detrimento dos que poderiam significar a proteção coletiva; normatizamse formas de trabalhar consideradas seguras. Assumida essa perspectiva, são imputados aos trabalhadores os ônus por acidentes e doenças, concebidos como decorrentes da ignorância e da negligência, caracterizando uma dupla penalização (Machado et al., 1995).

Em síntese, apesar dos avanços significativos no campo conceitual, que apontam um novo enfoque para lidar com a relação trabalho-saúde, consubstanciados sob a denominação de Saúde do Trabalhador, depara-se, no cotidiano, com a hegemonia da Medicina do Trabalho e da Saúde Ocupacional. Tal fato coloca em questão a já identificada distância entre a produção do conhecimento e sua aplicação, sobretudo num campo potencialmente ameaçador, onde a busca de soluções quase sempre se confronta com interesses econômicos arraigados e imediatistas, que não contemplam os investimentos indispensáveis à garantia da dignidade e da vida no trabalho.

\section{Discussão}

No Brasil, essa situação e relação entre influências das políticas públicas (incluídas as políticas voltadas para o trabalhador) e as mudanças das relações de trabalho se agrava pela incapacidade do setor saúde do Estado em reabsorver seu papel de intervir no espaço do trabalho. Essa tarefa, prevista na Reforma Carlos Chagas, de 1920 - interrompida com a criação, em 1930, do Ministério do Trabalho, Indústria e Comércio, que passou a assumila - foi resgatada na Carta Constitucional de 1988 e regulamentada pela Lei 8080 . No entanto, as marcas de um passado recente não são facilmente removíveis. Em meados de 1910, por exemplo, somente em grandes cidades, principalmente Rio de Janeiro e São Paulo, um nascente movimento operário, formado basicamente por imigrantes, começou a questionar a situação vigente das relações de trabalho e exigir direitos, como o de cidadania e melhores condições de saúde (Oliveira e Teixeira, 1986). A principal manifestação operária do período foi uma greve geral a cidade de São Paulo em 1917 (Oliveira e Teixeira, 1986)

As Delegacias Regionais do Trabalho advogam, em vários estados, a exclusividade de sua competência para inspecionar os centros produtivos. Essa posição, de um modo geral, encontra eco nos segmentos mais conservadores do patronato, na medida em que tais inspeções, orientadas por um modelo tradicional, pontuais e técnico-burocratas, incapazes de alimentar um sistema de vigilância em saúde do trabalhador, servem aos seus propósitos ao não promoverem mudanças significativas.

Da mesma forma, os Serviços Especializados em Segurança e Medicina do Trabalho (SESMT), instituídos em 1978, com algumas exceções, desviam-se da função de reconhecer, avaliar e controlar as causas de acidentes e doenças. Seus profissionais - assalariados

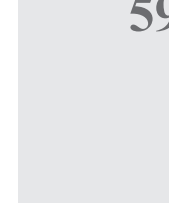

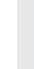

.

\section{(⿸丆口}


pela empresa e sem respaldo legal para contrariarem-lhe os interesses - restringemse à adoção de medidas paliativas diante dos riscos mais patentes.

A deficiência na formação de recursos humanos na área, consequência da marginalidade ainda atribuída à questão trabalho-saúde, aliada à generalizada insatisfação profissional, reproduz na rede pública a prática ineficaz dos SESMT, presente também em serviços conveniados com as empresas e com o próprio sistema público de saúde.

Essa desintegração, expressa em ações fragmentadas, desarticuladas e superpostas de instituições com responsabilidade direta ou indireta na área - agravada por conflitos de concepções e práticas, bem como de interpretação sobre competências jurídicoinstitucionais - revela a trajetória caótica do Estado em sua função de promover a saúde do cidadão que trabalha. Apenas o esforço isolado de profissionais que se articulam em programas de saúde do trabalhador, centros de referência e atividades de vigilância realmente efetivas, abre um rastro de luz nesse universo sombrio. Mas sua atuação é marcada, repetidamente, pela descontinuidade, quer por pressões externas dos que se sentem ameaçados em seu poder de tratar vidas humanas desgastadas pelo trabalho como rejeitos do processo produtivo, quer pela sucessão de novas administrações que não priorizam esses investimentos.

Por outro lado, a essa forma inconsequente de lidar com a saúde e a vida, une-se a resistência dos indivíduos em aceitar a condição de doentes. O medo de perder o emprego garantia imediata de sobrevivência - aliado aos mais variados constrangimentos que marcam a trajetória do trabalhador doente, "afastado" do trabalho, mascara, em muitos casos, a percepção dos indícios de comprometimento da saúde ou desloca-os para outras esferas da vida, inibindo ou protelando, frequentemente, ações mais incisivas de reivindicação às instâncias responsáveis pela garantia da saúde no trabalho.

No entanto, a evidência dos efeitos do trabalho em condições adversas é de tal ordem que extrapola os limites do conhecimento legitimado como científico e ganha espaço no âmbito do senso comum. É uma relação dada e inquestionável. Faz parte da vivência de trabalhadores, vítimas de doenças e acidentes, mesmo quando não obtêm êxito em comprovar sua origem na atividade exercida.

Mesmo assim, não restam dúvidas de que a inserção diferenciada dos indivíduos nos processos produtivos quer no meio urbano, quer no rural, definem padrões também diversificados de morbi-mortalidade, para os quais contribuem outros fatores decorrentes das condições de vida a que estão submetidos. Dessa forma, no mundo do trabalho revela a imensa gama de diferenças presentes na sociedade, onde tendem a reproduzir-se, inclusive, em seus antagonismos.

Nas duas últimas décadas, uma sucessão de eventos como a construção do Sistema Único de Saúde e as transformações sócioeconômicas vêm exercendo sobre as atuais concepções, a organização da assistência, a formação e a prática profissional em saúde.

A partir de meados da década de 90 o Estado brasileiro tem mudado seu perfil de atuação, de um Estado onipresente e prestador de serviços para um modelo mais enxuto e fiscalizador, de órgãos e entidades públicas ou não, conveniadas ou não. Para ser mais específico, a partir do ano 2000, pela lei $\mathrm{n}^{\circ}$ 9.961/2000, foi criado a Agência Nacional de Saúde Suplementar (ANS) com a atividade fim de organizar e regular o mercado de saúde privada no Brasil. A ANS é composta de várias diretorias com autonomia administrativa. É assinado um Contrato de Gestão com o Ministério da Saúde, em que os diretores têm mandatos a cumprir e metas a atingir, dentro dos respectivos mandatos. Os mais variados ramos da economia também experimentam este modelo. Os planos ou seguros de saúde privados, sob a lei n $\mathrm{n}^{\circ} 9.656$, ficam obrigados a atender integralmente os serviços médicos-hospitalares de patologias classificadas pela CID-10 (Classificação Internacional de Doenças), nos chamados "planos de referência", excetuando-se os serviços odontológicos.

Por outra vertente, na política de recursos humanos em saúde, o debate envolve a preparação e a qualificação dos trabalhadores para a saúde coletiva e do trabalhador, vislumbrando a consolidação de políticas de saúde tendo como objeto o trabalho/ 
trabalhador, a Estratégia de Saúde da Família (ESF), o Sistema Único de Saúde (SUS) e a garantia dos seus princípios fundamentais (Marsiglia, 2004).

O esforço de modificar a perspectiva tradicional do cuidado em saúde encontrou suporte nas mudanças ocorridas na saúde como um todo. Uma trajetória de inovações vem afetando os currículos e projetos políticos de ensino, em busca da formação de profissionais de saúde conhecedores dos problemas sociais e de saúde da população e capazes de intervir na reorganização do setor saúde (Faustino et al., 2003)

\section{Conclusão}

Os processos de reforma em saúde que têm proposto a descentralização, integralidade da atenção, entre outros preceitos, especialmente a partir da reforma sanitária brasileira, têm oscilado entre avanços e recuos contraditórios que traduzem as ambiguidades e conflitos que têm marcado as mudanças das funções do Estado, das políticas públicas de saúde e, concomitante a isso, a flexibilização/ precarização das relações de trabalho. Os estados vêm perdendo a capacidade de formular e implementar políticas nacionais de desenvolvimento (políticas industriais, de energia, de transportes, sociais etc.) que atenda à equidade social. As ações estatais cada vez mais se concentram em políticas monetárias e cambiais com metas fixadas em negociações com agentes financeiros internacionais sob pressão de "necessidades técnicas impostas pela globalização".

As políticas reformistas de saúde devem considerar as reformas no contexto das relações de trabalho que se estabelecem, naqueles países que historicamente adotaram essa modalidade de organização políticosocial do país, no sentido de estabelecer o adequado balanço de poder entre os governos centrais, estaduais e locais, redistribuindo competências na área da saúde levando em conta a diversidade do país, complexidade e os cenários de mudanças. Deve considerar, portanto, a diversidade dos determinantes do nível de saúde em termos geográficos, econômicos, sociais, culturais e demográficos, além das necessidades e do estado presente da oferta, acessibilidade e qualidade desejáveis dos serviços de saúde, ou então como mero reguladoras das políticas de saúde.

Por complexidade, entende-se a intensificação das mudanças tecnológicas em saúde, induzindo crescentes pressões para sua incorporação em segmentos privilegiados da população, coexistindo com fatores que reproduzem agravos, que fazem persistir o quadro de desigualdades em saúde. Os cenários de mudanças devem considerar a emergência de condições epidêmicas como as mortes por violências (homicídios, principalmente), patologias associadas à flexibilização/ precarização das relações de trabalho, doenças crônico-degenerativas (neoplasias malignas e doenças cardiovasculares) e HIV/ AIDS. Tais condições estão se agravando nas condições de vida deterioradas das populações pobres e social e etnicamente discriminadas, como resultado das políticas de ajuste, do desmantelamento do EstadoNação e do predomínio dos mercados sobre a cidadania/trabalho.

Nessa perspectiva, a SESMT, incluindo a Odontologia do Trabalho, se coloca como importante ferramenta frente aos desafios do "novo" papel do Estado, das relações de trabalho e do processo saúde-doença que, por conta disso, se estabelece.

Parapromovermudanças, os profissionais envolvidos com a Odontologia do Trabalho precisam construir uma agenda que leve em consideração eventos relevantes nessa área, neste início de século. O estágio da construção do Sistema Único de Saúde (SUS) baliza a possibilidade de realizar as ações que permitam atender às necessidades de todas as pessoas (princípio da universalidade), viabilizando seu acesso a todos os recursos odontológicos e de saúde geral de que necessitem (princípio da integralidade), e ofertando mais aos que mais necessitam (princípio da equidade). O SUS é, reconhecidamente, uma importante conquista social dos brasileiros, que se mostrou capaz de resistir à avalanche neoliberal que, nas últimas décadas, destruiu a maioria dos sistemas públicos de saúde na América Latina. Mas, reconhecer isso não significa desconsiderar os enormes problemas enfrentados pelo setor de saúde ; seja em decorrência das péssimas 
condições de vida da maioria (com grande impacto sobre os níveis de saúde), seja em consequência das dificuldades orçamentárias e gerenciais que marcam a administração pública, ou seja, ainda, pelos novos desafios que o mundo do trabalho moderno atinge aos trabalhadores.

\section{Referências}

1 - Bahia L. Mudanças e padrões das relações público-privadas: seguros e planos de saúde no Brasil. Tese de doutorado. Fundação Oswaldo Cruz, Rio de Janeiro, p.228. FUNENSEG,2000

2 - FREYRE G. Ordem e Progresso. Rio de Janeiro. Editora Globo, 2004

3 - FAUSTINO RLH, Moraes MJB, Oliveira MAC, Egry EY. Caminhos da formação de enfermagem: continuidade ou ruptura? Rev Bras Enferm 56(4): 343-47. 2003.

4 - GIOVANELLA L. Entre a Solidariedade e a Subsidiariedade: políticas de contenção no seguro social de doença alemão. Rio de Janeiro: Editora FioCruz, 1998.

5 - GUERSCHMAN S. A Democracia Inconclusa, um estudo da reforma sanitária brasileira. Rio de Janeiro: Editora FioCruz, 1995

\section{6 - LEVCOVITZ E; Lima LD; MACHADO}

CV. Política de saúde nos anos 90: relações intergovernamentais e o papel das Normas Operacionais Básicas. Ciência \& Saúde Coletiva, v. 6, n. 2, 259-291, 2001

7 - LEVCOVITZ E. Transição x consolidação: o dilema estratégico da construção do SUS - um estudo sobre as reformas da política nacional de saúde 1974-1986. Tese de doutorado, IMS/ UERJ,Rio de Janeiro, p. 286,1997.

8 - MACHADO JMH; Minayo-Gomes, C, . Acidentes de Trabalho: Concepções e Dados. In: Os Muitos Brasis: Saúde e População na Década de 80 São Paulo/Rio de Janeiro: Hucitec/Abrasco p.117-142,1995.
9 - MARSIGLIA RMG. Instituições de ensino e o Programa Saúde da Família: o que mudou?. Rev Bras Saúde Família. 5(7). 30-412004.

10 - NOSELLA, P. Trabalho e educação. In: Trabalho e Conhecimento: Dilemas na Educação do Trabalhador, São Paulo: Editora Cortez. p.27-42. 1989.

11 - OLIVEIRA JAA, TEIXEIRA SMF Previdência Social no Brasil-60 anos de História da Previdência no Brasil. Petrópolis:Vozes;1986

12 - PIERANTONI CR 2000. Reformas de saúde e recursos humanos: novos desafios $\mathrm{x}$ velhos problemas. Um estudo sobre recursos humanos e as reformas recentes da política nacional de saúde. Tese de doutorado, IMS/ UERJ, Rio de Janeiro p.228,2000.

13 - POCHMANN, M. Economia Social e do Trabalho, a superterceirização do trabalho. Editora LTR. São Paulo, 2008.

14 - RODRIGUES PHA, Santos IS. Saúde e Cidadania, uma visão histórica e comparada do SUS. Editora Atheneu. São Paulo, 2009.

15 - SANTOS BS. Da ideia da universidade à universidade de ideias. In: Santos BS. Pela mão de Alice: o social e o político na pósmodernidade. $9^{a}$ ed. São Paulo: Cortez; p. 186233, 2003.

Endereço para Correspondência:

Ministério do Desenvolvimento Social

Esplanada dos Ministérios, bloco C, $4^{\circ}$ andar, 447 CEP 70046-900 Brasília - DF

Tel:61 3433-1139

sylvio.junior@mds.gov.br 